\title{
EVALUATION OF AIR QUALITY IN KONYA CITY CENTER AFTER THE NEW CORONA-19 OUTPUT AND WITH ITS CAUTION
}

\author{
Sukru DURSUN ${ }^{1 *}$ \\ ${ }^{1 *}$ Konya Technical University, Environmental Engineering Department, Konya, Turkey; \\ *Corresponding Author Sukru DURSUN, e-mail: sdursun@ktun.edu.tr;
}

Received May 2021; Accepted June 2021; Published August 2021;

DOI: https://doi.org/10.31407/ijees11.401

\begin{abstract}
As in the changing conditions throughout the world, urbanization in Turkey, energy supply and the use of energy resources create significant effects on a global scale, and as a result, air pollution is an important environmental problem. It is known that the factors that cause air pollution have significant effects on human and environmental health. In order to reduce these effects, improving air quality is important all over the world. Scientists and relevant authorities are working on monitoring the values of pollutants to find solutions to air quality problems, to follow an effective path or to determine a strategy. It is also important to measure air pollutants and monitor the quality, and to determine the causes and sources of pollution. It is very important to spread or model the analysis processes over a wider area. It is possible to reach these parameter limits with the measures to be taken to improve the air quality parameters. In recent years, new stations have been established in addition to 4 air quality measurement stations in the center of Konya, and the daily average data obtained from these are evaluated in this study. It has been observed that some local factors are also effective, as all parameters change depending on seasonal conditions. In general, it is understood from the results of studies that the air quality decreases and the size of pollution increases in cold winter seasons. It is necessary to reduce the pollution values, to control the pollutant rate arising from the activities of industrial enterprises, to reduce the use of fossil fuels, to encourage urban public transportation, to protect nature, and to make legal arrangements in human activities that reduce air quality. The studies to be carried out for this purpose should be started by the relevant authorities in order to reduce the factors causing pollution and to protect the air quality. It should be the duty of humanity to take measures to protect the life of all living things, especially human health.
\end{abstract}

Keywords: Konya, Air Quality, PM, COVID 19, outbreak 